\title{
Challenges of the growing African cement market - environmental issues, regulative framework, and quality infrastructure requirements
}

\author{
Wolfram Schmidt ${ }^{1}$, Inès L. Tchetgnia Ngassam ${ }^{2}$, Gerhard Breitschaft ${ }^{3}$, and Stephen Virchow ${ }^{4}$ \\ ${ }^{1}$ Bundesanstalt für Materialforschung und -prüfung, Department "SafetyofStructures", Berlin, Germany \\ ${ }^{2}$ University of Cape Town, Department of Civil Engineering, Cape Town, South Africa \\ ${ }^{3}$ Deutsches Institut für Bautechnik (DIBt), President, Berlin, Germany \\ ${ }^{4}$ Physikalisch-Technische Bundesanstalt (PTB), Department "International Cooperation“, Braunschweig, Germany
}

\begin{abstract}
The African cement, concrete and construction business is growing at rapid pace. The cement sales are expected to grow rapidly until 2050. The number of newly built cement plants increases dramatically and in addition more cements are being imported from outside the continent, e.g. from Turkey, Pakistan, Indonesia, and China, driven by overcapacities in the countries of origin. This causes a high number of potentials and challenges at the same time. Newly built cement plants can operate directly at best technological state of the art and thus incorporate more sustainable technologies as well as produce new and more sustainable products such as cements blended with sustainable supplementary cementitious materials such as calcined clays, and industrial or agricultural by products. At the same time the new variety of binding agent as well as the international imports, which are driven by price considerations, make the cement market prone to quality scatter. This puts pressure on the quality control regulations and institutions to ensure safety of construction, healthy application, and environmental safety for the population. The paper presents possible solutions to build up the rapidly increasing African cement production more sustainably than in the rest of the world as well as the related challenges and obstacles that need to be overcome. Based on experiences with a series of panAfrican cement testing laboratory proficiency schemes conclusions are made on technical, regulative and political level.
\end{abstract}

\section{Cement and construction technology from a global point of view}

Concrete construction has always been a local business of global concern. Due to the indispensable nature of concrete, globally and locally the material has an enormous ecologic, economic and social dimension.

Concrete makes out $50 \%$ of everything the world produces [1]. It consists of the elements that form $98 \%$ of the outer Earth's crust [2]. Regardless of their possible performance, materials based on the complementary $2 \%$ are not feasible for building global infrastructures and habitats, due to the limited volume of required resources.However, it has also pointed out that compared to other construction materials concrete shows the lowest embodied energy and the lowest embodied carbon [3].

The global cement demand is predicted to increase from 4.6 Gt/a [4] in 2015 to about 6-13.5 Gt/a until 2050 $[3,5]$. Based on the high global production volume, concrete today is responsible for $5-10 \%$ of the global $\mathrm{CO}_{2}$ exhaust [1]. In 2050 it can be as much as one third [4].

Concrete is affordable and can be produced everywhere in the world from mainly local resources.It is often called a "democratic" material, since despite its global business, it always involves a many local businesses and players.It empowers 545,000 employees worldwide. The annual turnover is 17.5 billion EUR [5].

Eventually, concrete is inevitable for infrastructures that are lifelines for local developments and triggers of global networking. And, concrete is of highest importancefor adequate housing that gives shelter and safety, and thus lets the populace participate in the wealth and growth of economies. It therefore provides the foundation for adequate life and future perspectives, which contributessignificantly to reduction of global social problemse.g. related to health, social unrest, or migration.

Hence, cement and concrete technologies are inevitable in the world with an increasingly important role for developing economies. Due to the enormous global impact, it will become more important to use cement and concrete more sustainably. Recommendations for a more eco-efficient cement and concrete based industry were made available recently in a UNEP report [6]. However, despite the environmental and economic 
aspects, it is also important to build with cement and concrete in a safe and qualitatively sound way.

\section{Challenges in the growing African cement and construction market}

\subsection{Perspectives and peculiarities of the African cement and concrete market}

Many African countries are booming with steady and increasing velocity. Along with the economic upturn come the construction activities. Without any doubts, the numerous challenges that can be identified regarding housing and infrastructure can only be mastered by opting for cement and concrete as building material.

The African continent has numerous regions with different boundary conditions, and not every region provides the best potential for cement production [7]. The lack of typical industrial by-products such as fly ash (FA) and ground granulated blast furnace slag (GGBS) makes saving of ordinary Portland cement a challenge. However, less established local alternatives do exist and will be discussed later in this paper.

Despite the great regional differences in Africa a few peculiarities can be observed nearly everywhere over the continent. The variety of cements available in subSaharan Africa is generally limited. While modern cement technology considers cement blending as mean to individualise the cement performance and increase the number of marketable products, the variety of cements on the sub-Saharan African market is rather limited to OPC, and limestone filler or pozzolana blended cement. South Africa with huge deposits of FA and certain availability of GGBS is an exception. In order to serve the market with GGBS or fly ash blended cement types, the raw materials are sometimes shipped in, although from global perspective shipments of huge materials volumes does not make sense regarding the global carbon emissions.

Cement plants are being rapidly built today in Africa, but to date the density of cement plants is still low. The related transportation costs cause high local prices for cement, so that building with concrete is extremely expensive for local builders. This encourages global cement exporters to ship materials from all over the world into Africa. The implications are:

- High pressure on local cement producers

- A vast variety of cement types and producers

- Challenges in quality and safety regulations

While cement prices expressed in local purchasing power are significantly higher, labour costs are typically low in Africa compared to other parts of the world, since in construction business workers are commonly paid upon requirement and on daily basis. The cost positions for the calculation of concrete constructions thus significantly diverge from European calculations.However, not only the costs diverge, but also the entire boundary climatic and infrastructural framework:
- Most African regions have high temperature and often high relative humidity, while most standards were developed in moderate climate.

- Transportation distances for raw materials are long, time intensive, and costly.

- Neither pre-cast nor ready-mixed concrete are well established. Mostly cement, sand, and aggregates are stored and mixed on the construction site.

- Poker compaction and automated mixing is not always and everywhere available. Many process steps during casting are largely conducted manually. However, this does not generally apply. Many large scale construction projects such as dams, airports, or central infrastructures are operated at a high technological level. The result is that, eventually, cement and concrete technological regulations need to cope with a much wider variety than e.g. in Europe, from very simple to very sophisticated. Due to the vast differences between the African boundary framework and the framework of the European continent it is questionable whether a European regulative framework can be an ideal role model for countries in Africa[8].

\subsection{Sustainability potentials in Africa}

While in the past concrete performance was linked to the content of OPC and the water-cement ratio, today, high quality concrete can be produced with low clinker cement types and due to the use of chemical admixtures, the water-cement ratio can be minimised, thus allowing to optimise the cement use in concrete. Therefore today'slow per capita cement consumption in most African countries can turn out to become an enormous potential for Africa to spearhead sustainable cement and concrete technologies [9], since the predicted growth of the construction market can be conducted at best level of available knowledge without repeating past mistakes and without using unnecessarily high amounts of cement.

\subsection{Experiences from a pan-African cement testing proficiency scheme}

Although there is a distinct demand for high quality products in the African society, the infrastructure to meet the demand mostly needs improvement. Particularly in the growing construction market with an increasing number of materials in use, it is most important to develop efficient quality assessment and control schemes, since this market is crucial for Africa's development, and affects the safety of the entire population.

Results from a pan-African cement proficiency testing scheme (PACE-PTS), which is conducted as cooperation between BAM Federal Institute for Materials Research and Testing and the German Metrology Institute (PTB) with support of the University of Cape Town illustrate the challenges related to quality control procedures in the cement and concrete area. In the PACEPTS, laboratories conduct cement, binder and aggregate testing with identical reference materials provided by BAM according to formerly agreed upon procedures and report back their results. Furthermore, the laboratories 
were requested to conduct some of the tests in addition with local cement types.

This gives opportunity for public and private laboratories to self-assess their performance and to increase their network and skill in a final evaluation workshop. In the 2016/2017 scheme 55 laboratories from 25 countries, 22 of which from Africa, have participated (Figure 1). Most laboratories were from sub-Saharan Africa with strong participation from S. Africa, Nigeria, Ghana, Angola, and Kenya.

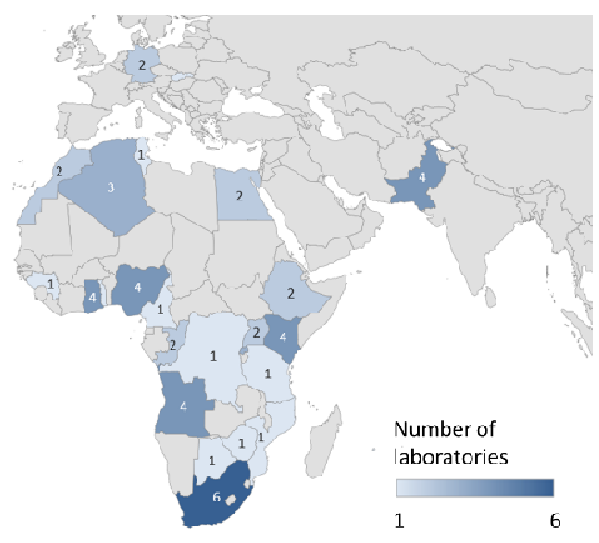

Figure 1: Distribution of registered laboratories for the PACE-PTS in 2016/2017.

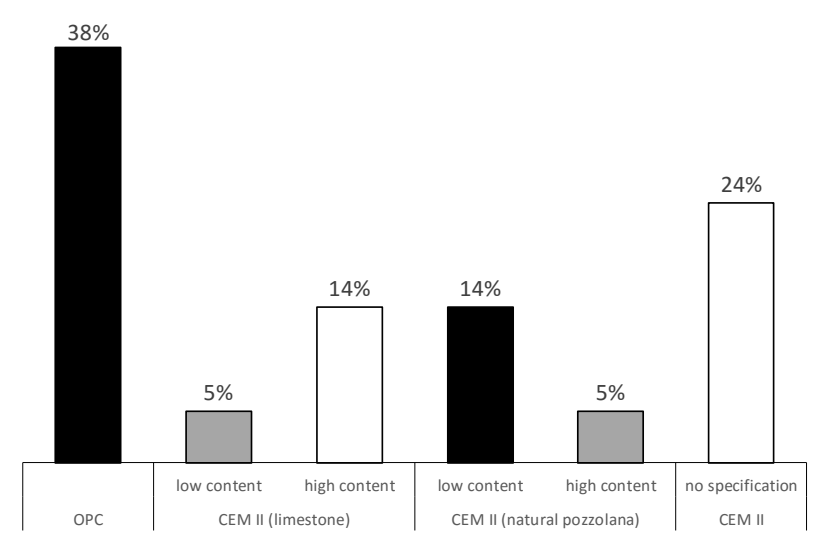

Figure 2: Local cement types used and percentages.

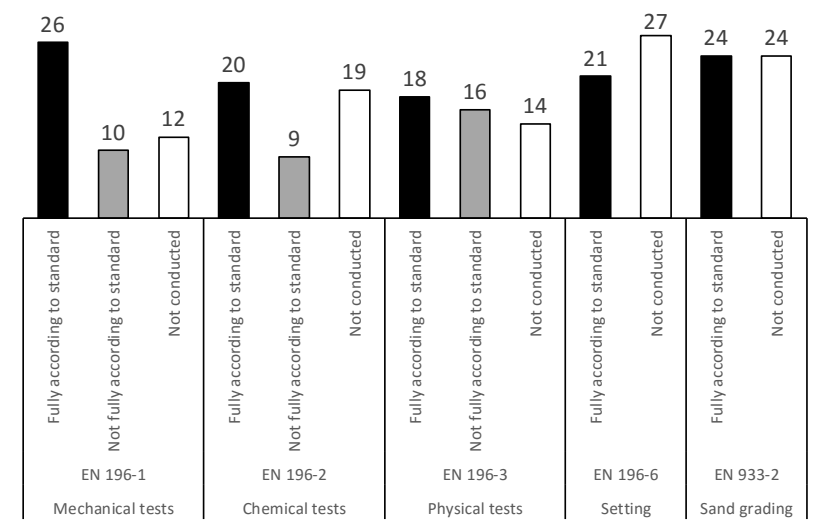

Figure 3: Distribution of registered laboratories for the PACE-PTS in 2016/2017.

Figure 2 shows the usage of different cement types for the African laboratories. It can be found that $72 \%$ of the local cement types were blends, the majority of which blended with limestone filler or natural pozzolana. A high percentage of cements were only classified as CEM II without further specification. The diversity of different cement types used, and the fact that limestone filler and natural pozzolana dominated, both of which are prone to performance scatter, indicates that proficiency in testing becomes very important for the safety of construction, but as shown in Figure 3, in many experiments less than half of the laboratories could conduct the testing fully according to the standards. The reasons were manifold, such as lack of equipment or lack of possibility to adjust and maintain the required laboratory climate.

\subsection{Challenges for quality control}

In order to make use of the existing potentials for more sustainable cement and concrete construction technologies, in the future, mixture compositions have to be more complex than in the past $[6,10]$. Besides the classical components for concrete, cement, water and aggregates, further components, such as chemical admixtures and mineral additions are used.

Particularly industrial and agricultural waste products as well as organic compounds can become a threat to the population, and shall be carefully used, while it is also necessary to see the potential of immobilising certain compounds in concrete structures. These changes and the increasing need for the associated quality control lead to an even higher requirement of well-equipped laboratories with well-schooled staff members. Both requirements are not always met as the results of arecent and past pan-African cement testing proficiency schemes (PACE-PTS) have indicated $[11,12]$.

Other challenges for efficient quality control in the African cement and construction market include the lack of legally binding requirements to guarantee users' security. Besides, functioning market surveillance schemes are rare in most countries in the region which could lead to serious accidents such as collapsing buildings. Customers' lacking awareness of the importance of quality control in the market additionally challenges the development of laboratories in this market, since the demand might be too weak, though past proficiency testing schemes indicated a definitively increasing demand for quality control.

\subsection{Challenges for a safe construction framework}

To supply African markets with reliable construction products in the long run, it is important to have appropriate legal provisions. Unfortunately, there have been various buildings that collapsed due to inadequate execution of works and improper construction products recently, causing injury and worse.The required safety can only be provided by government initiatives.

As a first step, governmentshave to draw up the requirements for construction works that shall be binding in their countries. These requirements first and foremost include safety issues such as stability, fire protection, health and environmental protection as well as secondly 
building physical properties such as acoustic and thermal insulation - where needed. Legal requirements can be kept quite general in the law, as long asthey are specifiedfor users and appliers in more detail through technical specifications.

For example, it is important to define acceptable failure probabilities for load-bearing components or necessary fire resistance durations for certain building sections, or tolerable elution to the groundwater. These requirements then lead to specifications for construction products. To make sure that construction products meet thespecifications permanently and reliably, it is necessary to establish a system of certifications, control and inspections. This system does not inevitably have to be run under government responsibility, but it can also be private run. In either case, it needs to be tailored to the economic and political situation of each country. It is not advisable to adopt European or American systems and apply them in Africa without reasonable and careful adaption.

\subsection{Standard challenges}

Developing standards is vital to guarantee consistent and reproducible quality for construction products and construction works. As mentioned before, climatic and economic differences make it necessary for Africa to develop own standards or adapt those from other continents carefully and reasonably based on expert knowledge.Particularly the adjustment of a uniform temperature seemed to be a major challenge during the PACE-PTS scheme. The reported testing temperatures varied between $10{ }^{\circ} \mathrm{C}$ and $30^{\circ} \mathrm{C}$. A reasonable standard has to take this into account, and still provide uniform test specifications, tolerances, evaluations, calculation methods as well as implementation rules etc. to ensure a reliable system, provided it be monitored adequately.

\section{Solution strategies}

\subsection{Way forward}

The boundary framework for cement and concrete construction varies greatly from conditions in Europe. Existing solutions that were developed elsewhere cannot master the challenges of Africa in an ideal way and the full potentials in Africa cannot be tapped. To create the best available solutions, construction technologies and materials need to be developed in Africa based on short supply chains, tailored regulative frameworks and policies. While international experts can support processes, the final decisions have to be made by local experts.

\subsection{Solutions for alternative materials}

Today, it is undisputed that binder has to be reduced in OPC clinker in order to minimise the carbon emissions related to cement production [6]. One of the most promising ways to develop sustainable cement types is the use pozzolanic materials, or calcined clays.
Limestone calcined clay cement have pointed out to be very eco-efficient and sustainable $[1,13-16]$, the resources for which are abundantly available all over Africa. Since a high number of cement plants will be required in the future all over the continent, the limestone calcined clay technology can directly be implemented with a reasonable market acceptance and an adequate regulative framework.

However, while clay materials will assumedly have an enormous global impact, alternative solutions might have a high potential locally. Africa has a huge and growing agricultural sector [17], which creates a large number of by products that are not adequately used to date [18]. For example, due to its high amorphous silica content, rice husk ashespoint out to be most excellent cementitious materials that can outperform OPC by far[18, 22, 24-28]. Further alternatives exists, such as ashes from cassava peels [19], sugar cane bagasse, groundnut shells, locust beans or bamboo leaves[20], which have shown to be suitable for both low-end and high-end performance applications [21-23]. Their use is extremely promising, considering that Africa provides $60 \%$ of all globally yet unused arable land [17]. Particularly Africa's economic growth is closely linked to the agricultural sector. The development of plant based cementitious binders and concrete additions is therefore future oriented and sustainable with enormous growth potential.

Sustainable construction also requires to use cement in concrete more efficiently. Today, various petrol based chemical admixtures help to produce higher strength concrete with less cement [18, 19]. The use of polycarboxylate ether superplasticizers has become quite common in concrete technology due to their versatility $[10,30]$. However, their uncomplicated and cost efficient availability is limited in most countries in Africa [22, 24]. They have to be shipped in from overseas, which creates additional global warming potential.

Locally easy accessible alternatives are available. Lignosulphonates are by-products of the cellulose industry and they can well enhance the concrete properties [9, 22]. Furthermore, Acacia gum from the Karoo and Arabic gum from Sudan can have positive influence on set retardation as well as flow performance[9, 31, 32]. These are just examples of many alternatives, which do not need complex processing to become ready to use. Furthermore, fibres can be used to enhance the ductility. For structural applications, typically steel fibres are used. Alternative fibres can be found again from bio-based sources such as sisal an coconut fibres [23]. They have to become more brittle due to ageing. However, their deterioration can be reduced by immersion in silica fume slurry [33, 34]. Since this may not be the most cost effective treatment, in the future, it might be interesting to observe whether a solution in silica from rice husk ash can have a similar effect.

Therefore, the African continent provides a high number of materials, which seem to be technologically promising and significantly more sustainable than established materials. However, their usage is typically not covered in existing standards. The materials and 
technologies have potentials to become globally similarly or more sustainable than existing technologies. Their rapid implementation can help to overcome some of the most pressing challenges in Africa, that are housing and infrastructure, while in parallel new local value chains can be created thus fostering the economic growth and the independence of international monetary flows.

Hence, the African markets need to develop rapidly quality surveillance infrastructures that form a reasonable compromise between support of the verve for innovation and provision of adequate safety.

\subsection{Enhanced quality infrastructure}

In order to improve the whole system of quality control, an enhancement of national and regional systems of quality infrastructure is necessary. Testing is part of the national quality infrastructure, which is understood as a complex network of metrology, standardisation, testing, certification, and accreditation. To guarantee the reliability of their results, testing laboratories must ensure that their devices are properly calibrated and thus the results are traceable to national and international measurement standards [35]. Furthermore, laboratories should use quality management systems and work according to defined procedures. Proficiency testing schemes are one efficient tool to compare installed measures.

The current state of national quality infrastructure systems in Africa is heterogenous. On the one hand, there is a positive development throughout Africa. Since 2014, improvements in 32 national systems could be registered. On the other hand, there is still room for improvement. Around half of African states have national quality infrastructure systems which are not in accordance to international requirements. [36]

While the need for qualified testing laboratories is obvious, the current state of quality infrastructure in most African countries does not necessarily support such laboratories. Consequently, it is difficult for them to calibrate their instruments in a cost and time efficient way. Furthermore, support for the introduction of quality management systems and accreditation is not always easy to get. Besides measures to enhance the national quality infrastructure, another solution might be the division of labour on a regional level. This might include e.g. regional reference laboratories, regional market surveillance schemes as well as regional capacity development.

\subsection{Research capacity}

The series of 25 tests, which were selected by the participants of the first PACE-PTS series in 2012/2013 [37] and amended by further investigations over the course of the years, were divided in "standard cement tests" and "advanced tests". The first group comprises of the mechanical, chemical and physical testing according to the standards, the latter group comprises of further mechanical tests,sand evaluation, andmore sophisticated rheological testson interactions between cement and superplasticizers following a procedure developed at BAM.

Table 1 presents the numbers and percentages of laboratories that conducted part of the tests or all tests. It can be found that many laboratories do not provide the adequate equipment to conduct all required tests. $20 \%$ of the laboratories registered for the PACE-PTS were from cement producers (Figure 4). These laboratories are typically well equipped to perform the required testing. However, about $80 \%$ of the participating laboratories were either university laboratories, governmental laboratories or private laboratories. Since these laboratories ensure the public safety, that lack of equipment for standardised tests is alarming. Considering that university and private laboratories are furthermore driving forces for innovation, it is getting obvious that investment in research capacity must include investment in up to date equipment.

A way to finance the relevant investments could be to create central excellence laboratories that cooperate with universities and private laboratories as well as more public private partnerships.

Table 1: Numbers and percentages of tests conducted by the African laboratories for the PACE-PTS.

\begin{tabular}{|c|c|c|c|c|c|c|}
\hline \multirow{4}{*}{ 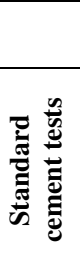 } & \multicolumn{2}{|c|}{$\begin{array}{c}\text { Type and } \\
\text { number of tests }\end{array}$} & \multicolumn{2}{|c|}{$\begin{array}{l}\text { Laboratories that } \\
\text { conducted tests }\end{array}$} & \multicolumn{2}{|c|}{$\begin{array}{l}\text { Laboratories that } \\
\text { conducted all tests }\end{array}$} \\
\hline & $\begin{array}{c}\text { Mechanical } \\
\text { tests }\end{array}$ & 6 & 37 & $77 \%$ & 28 & $58 \%$ \\
\hline & $\begin{array}{c}\text { Chemical } \\
\text { tests }\end{array}$ & 4 & 42 & $88 \%$ & 23 & $48 \%$ \\
\hline & $\begin{array}{c}\text { Physical } \\
\text { tests }\end{array}$ & 6 & 46 & $96 \%$ & 18 & $38 \%$ \\
\hline \multirow{3}{*}{ 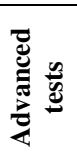 } & $\begin{array}{c}\text { Mechanical } \\
\text { tests }\end{array}$ & 4 & 38 & $79 \%$ & 20 & $42 \%$ \\
\hline & $\begin{array}{c}\text { Rheological } \\
\text { tests }\end{array}$ & 4 & 38 & $79 \%$ & 25 & $52 \%$ \\
\hline & Sand test & 1 & 26 & $54 \%$ & 26 & $54 \%$ \\
\hline
\end{tabular}

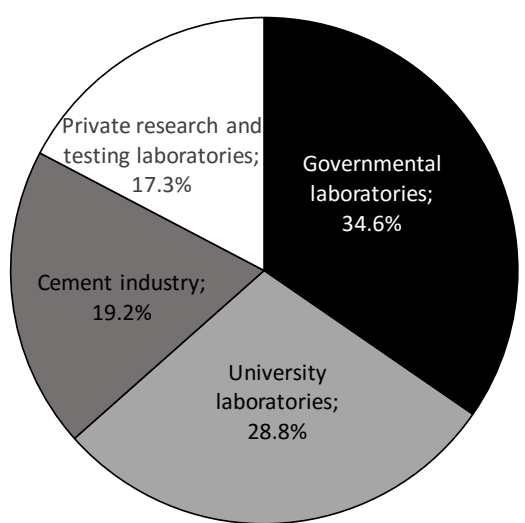

Figure 4: Percentages of laboratory types.

\subsection{Improved framework for safe construction}

Establishing a functioning system for controlling and inspecting construction products and the execution of construction works is costly and time intensive. However, such a system is inevitable for keeping the general public safe from damage caused by collapsing buildings, fire or hazardous materials and products. Each society 
determines which risks it is willing to take in this area, and how much money can be spent on control systems.

Europe uses different ways to ensure safety[38], depending on whether the construction products and construction works are standardised or new and innovative; whether they serve an important function within the building or are less relevant. These control and inspection systems can only serve as a rough model for Africa. They have to be adapted to the local circumstances. A network of laboratories is necessary as well as independent organisations (state-run and/or private) which check each other's results to ensure that only high-quality products enter the markets. Independence and mutual control are vital to prevent mistakes, fraud and corruption. This applies just as much to Europe as it does to Africa.

\section{Summary and conclusions}

The entire African continent provides huge potentials to develop a more sustainable cement and concrete construction market than in the rest of the world. However, the African continent also has its own challenges and peculiarities, which hinder timely tapping of the full potentials.

Africa provides a variety of local materials that can be used in cement and concrete construction that are comparable or better than existing materials used in other parts of the world. The short supply chains ensure local market growth combined with low environmental impact. Besides natural mineral resources, agricultural wastes provide manifold potentials regarding use as supplementary cementitious materials, chemical admixtures, and fibrous constituents.

For the implementation of these future oriented technologies, it is required to re-think the respective quality infrastructure and normative framework:

- The regulative framework and the quality infrastructure should have a strong focus on African demands.

- Concepts have to be innovation driven and target the African markets, yet ensuring public safety.

- In order to cope with the much higher variety of future cements and materials, research capacity and adequate equipment are inevitable.

- Central excellence laboratories can help keeping cost for equipment low, and public private partnerships can support sustainable quality infrastructures, when independence can be guaranteed.

\section{Acknowledgements}

The project is financed by the Federal Ministry for Economic Cooperation and Development

\section{References}

[1] K. Scrivener, "Realistic options to meet the challenge of increasing concrete demand in Africa
(Presentation)," presented at the 2nd International Conference on Advances in Cement and Concrete Technology in Africa, Dar es Salaam, Tanzania, 2016.

[2] P. Wray and K. Scrivener, "Straight talk with Karen Scrivener on cements, CO2 and sustainable development," American Ceramic Society Bulletin, vol. 91, pp. 47-50, Jun-Jul 2012.

[3] L. Barcelo, J. Kline, G. Walenta, and E. Gartner, "Cement and carbon emissions," Materials and Structures, vol. 47, pp. 1055-1065, 2014.

[4] K. Carstensen and O. Rapf, "A blueprint for a climate friendly cement industry," WWF, Nürnberg, Germany2008.

[5] CEMBUREAU, "Cement \& concrete: key facts \& figures," t. E. c. association, Ed., ed, 2015.

[6] K. Scrivener, V. M. John, and E. M. Gartner, "Eco-effcient cements: Potential, economically viable solutions for a low-CO2, cement-based materials industry," United Nations Environment Programme2016.

[7] W. Schmidt, N. N. M. Hirya, D. Bjegovic, H. C. Uzoegbo, and S. G. Kumaran, "Cement technology in sub-Saharan Africa-Practical and scientific experiences," American Ceramic Society Bulletin vol. 91, p. 82, 2012.

[8] W. Schmidt, A. Radlińska, C. Nmai, A. Buregyeya, W. L. Lai, and S. Kou, "Why does Africa need African concrete? An observation of concrete in Europe, America, and Asia - and conclusions for Africa," in International Conference on Advances in Cement and Concrete Technology in Africa, Johannesburg, South Africa, 2013, pp. $1139-1148$.

[9] W. Schmidt, "Why Africa can spearhead innovative and sustainable cement and concrete technologies globally," in KEYS Knowledge Exchange for Young Scientists: Valorisation of Industrial By-products for Sustainable Cement and Concrete Construction - Improvement of Solid Waste Management, N. S. Msinjili and W. Schmidt, Eds., ed Accra, Ghana: BAM, 2016, pp. 7-19.

[10] W. Schmidt, M. Sonebi, H. J. H. Brouwers, H.-C. Kühne, and B. Meng, "Rheology modifying admixtures: The key to innovation in concrete technology - a general overview and implications for Africa," Chemistry and Materials Research, vol. 5, pp. 115-120, 2013.

[11] W. Schmidt and G. Gluth, "Knowledge transfer and quality assurance - key factors for the future prospects of building with cement in Africa / Wissentransfer und Qualitätssicherung Schlüsselfaktoren für die Zukunftsperspektiven der Bauweise mit Zement in Afrika," ZKG International, vol. 65, pp. 34-38, 2012.

[12] W. Schmidt, H. C. Uzoegbo, N. Bella, G. Rongai, H. C. Kühne, and T. Diergardt, "Cement Testing in Africa - Conclusions from the First AfricaWide Proficiency Testing Scheme," Civil and Environmental Research, vol. 4, 2013. 
[13] S. S. Berriel, A. Favier, E. R. Dominguez, I. R. S. Machado, U. Heierli, K. Scrivener, F. M. Hernandez, and G. Habert, "Assessing the environmental and economic potential of Limestone Calcined Clay Cement in Cuba," Journal of Cleaner Production, vol. 124, pp. 361369, Jun 2016.

[14] F. Avet, R. Snellings, A. Alujas, M. Ben Haha, and K. Scrivener, "Investigation of the reactivity of various grades of kaolinitic calcined clays used as partial clinker substitute," in Advances in Cement and Concrete Technology in Africa, Dar es Salaam, Tanzania, 2016, pp. 137-142.

[15] L. M. Vizcaino-Andres, S. Sanchez-Berriel, S. Damas-Carrera, A. Perez-Hernandez, K. L. Scrivener, and J. F. Martirena-Hernandez, "Industrial trial to produce a low clinker, low carbon cement," Materiales De Construccion, vol. $65,2015$.

[16] A. Alujas, R. Fernandez, R. Quintana, K. L. Scrivener, and F. Martirena, "Pozzolanic reactivity of low grade kaolinitic clays: Influence of calcination temperature and impact of calcination products on OPC hydration," Applied Clay Science, vol. 108, pp. 94-101, May 2015.

[17] A. Perry, The Rift: A New Africa Breaks Free: Little, Brown and Company 2015.

[18] N. S. Msinjili, W. Schmidt, A. Rogge, and H. C. Kühne, "Optimising available resources for production of good concrete properties," in Advances in Cement and Concrete Technology in Africa, Dar es Salaam, Tanzania, 2016, pp. 323332.

[19] K. A. Olonade, "Cassava Peel Ash: An Emerging Pozzolanic Material," in 1st Symposium on Knowledge Exchange for Young Scientists (KEYS) - Sub-Saharan African Standards for Cement and Concrete Research and Raw Materials, Quality Control and Maintenance of Cementitious Products, Dar es Salaam, Tanzania, 2015, pp. 7781.

[20] I. C. Mayowa, "Making Durable Concrete Through Inhibition of Chloride Ion Penetration by Pozzolanic Reaction," in 1st Symposium on Knowledge Exchange for Young Scientists (KEYS) - Sub-Saharan African Standards for Cement and Concrete Research and Raw Materials, Quality Control and Maintenance of Cementitious Products, Dar es Salaam, Tanzania, 2015, pp. 145150.

[21] T. T. Loan and P. Navard, "Treatments of plant biomass for cementitious building materials - A review," Construction and Building Materials, pp. 131-176, 2016.

[22] W. Schmidt, N. S. Msinjili, H. C. Uzoegbo, and J. K. Makunza, "Admixture Concepts for the SubSaharan African Environment with Indigenous Raw Materials," in SP-302 Eleventh International Conference on Superplasticizers and Other Chemical Admixtures in Concrete, V. M. Malhotra, Ed., ed, 2015, pp. 491-505.
[23] W. Schmidt, N. S. Msinjili, S. Pirskawetz, and H. C. Kühne, "Efficiency of high performance concrete types incorporating bio-materials like rice husk ashes, cassava starch, lignosulfonate, and sisal fibres," in First International Conference on Bio-based Building Materials, ClermontFerrand, France, 2015.

[24] W. Schmidt and N. S. Msinjili, "SCC: a solution to the challenges of concrete construction in Africa," Concrete trends - Journal of the African cement and concrete industry, pp. 16-20, 2014.

[25] J. L. Akasaki, A. R. B. Vasconcelos, J. Payá, D. R. O. Assi, M. V. Borrachero, M. M. Tashima, J. L. Melges, and C. F. Fioriti, "Durability Of HighPerformance Concrete With Addition Of Rice Husk Ash And Rubber Tire," in 13th International Congress on the Chemistry of Cement, Madrid, Spain, 2011.

[26] G. C. Cordeiro, R. D. Toledo Filho, and E. M. R. Fairbairn, "Influence of Rice Husk and Sugar Cane Bagasse Ultrafine Ashes on Hydration Characteristics of Cement Based Pastes," in 13th International Congress on the Chemistry of Cement, Madrid, Spain, 2011.

[27] G. Rodríguez de Sensale, C. Romay, and F. Costa, "Waste Valorization From the Burning of Rice Husk," in 13th International Congress on the Chemistry of Cement, Madrid, Spain, 2011.

[28] W. Wilson and A. Tagnit-Hamou, "Workability and Hydration of Superplasticized Cementitious Mixtures with Rice Husk Ash," Aci Materials Journal, vol. 111, pp. 491-500, Sep-Oct 2014.

[29] W. Schmidt, N. S. Msinjili, and H.-C. Kühne, "Rheological Optimisation for Flowable Mixture Compositions Specified for African Boundary Conditions," in International Conference on Advances in Cement and Concrete Technology in Africa, Johannesburg, S. Africa, 2013, pp. 359366.

[30] W. Schmidt, H. J. H. Brouwers, H. C. Kuehne, and B. Meng, "Influence of Environmental Temperatures on the Performance of Polymeric Stabilising Agent in Fresh Cementitious Materials," Polymers in Concrete, vol. 466, pp. 97-104, 2011.

[31] R. Mbugua, R. Salim, and J. Ndambuki, "Effect of Gum Arabic karroo as a Water-Reducing Admixture in Concrete," Materials, vol. 9, Feb 2016.

[32] R. Mbugua, R. Salim, and J. Ndambuki, "Utilisation of Gum Acacia Karoo as Set-retarding Water-reducing Admixture in Cement Mortar and Concrete at Optimum Dosage," in 1st Symposium on Knowledge Exchange for Young Scientists (KEYS) - Sub-Saharan African Standards for Cement and Concrete Research and Raw Materials, Quality Control and Maintenance of Cementitious Products, Dar es Salaam, Tanzania, 2015, pp. 97-101.

[33] R. D. Toledo, K. Ghavami, G. L. England, and K. Scrivener, "Development of vegetable fibremortar composites of improved durability," 
Cement \& Concrete Composites, vol. 25, pp. 185196, Feb 2003.

[34] R. D. Toledo, K. Scrivener, G. L. England, and K. Ghavami, "Durability of alkali-sensitive sisal and coconut fibres in cement mortar composites," Cement \& Concrete Composites, vol. 22, pp. $127-$ 143, Apr 2000.

[35] C. Sanetra and R. M. Marbán, "The answer to the global quality challenge: a national quality infrastructure.," 2007.

[36] PTB, "PAQI, 2017: Pan-African Quality Infrastructure. Stocktaking Document 2017 (in preparation)," 2017.

[37] W. Schmidt, "Start of round-robin test for cement testing in Africa / Start für Ringversuch zur Zementprüfung in Afrika," BFT international : concrete plant + precast technology, vol. 08, pp. 54-55, 2012.

[38] G. Breitschaft, "Safe Construction Works Made of Reliable Construction Products," presented at the 2nd International Conference on Advances in Cement and Concrete Technology in Africa, Dar es Salaam, Tanzania, 2016. 